\title{
Influence of chemical additives on the properties of polymer foams
}

\author{
Michail Bruyako ${ }^{1}$, Larisa Grigoreva ${ }^{1, *}$ and Stepan Lvov ${ }^{2}$ \\ ${ }^{1}$ Moscow State University of Civil Engineering, Yaroslavskoe shosse, 26, Moscow, 129337, Russia \\ ${ }^{2}$ LLC Architectural and design bureau «APBP», 125430, Moscow, Russia
}

\begin{abstract}
Products based on thermosetting plastics have a variety of applications. One of the directions is thermal insulation. Filling foams provide excellent thermal insulation, due to the most optimal ratio of weight, strength and durability. Such heat-insulating materials work in a wide range of operating conditions. The article presents data on the study of the effect of chemical additives on the reduction of the acid number and the reduction in the corrosivity of foam plastics. The greatest efficiency in reducing corrosion activity has composition based on dihydrate of stannous chloride (II) with calcium oxide in a ratio of 2: 0.5 . The data on the change in the multiplicity of foaming when introducing chemical additives containing the same name cation and an anion of the same name are presented.
\end{abstract}

\section{Introduction}

Modern composite materials partially or completely replace traditional building materials. This is due to the fact that the composites have a wide variety of properties. The matrix of polymer composites is represented by polymers, they determine the properties of the material. Application is found both in thermoplastics and in thermosets.

Thermoset polymers are used to create thermal insulation materials, roofing coatings, pipelines, sealants [1]. The book [2] gives an overview of available polymeric composite materials, biopolymers, high-temperature plastics, thermoplastic elastomers. The authors paid attention to the polymers obtained by the interaction of aldehydes, amines, phenols. Composites based on phenol-formaldehyde resins (FPS) have high resistance, better resistance to freeze-thawing than steel and concrete [3]. As hetero-insulation materials, heterochain polymers containing urethane groups have proved to be successful [4].

Despite the fact that the FPS received and began to be used at the beginning of the 20th century, interest in them has not died away. Thermal insulation materials based on them are stable during operation, waterproof, have low combustibility. The possibility of using nanotechnologies in the development of polymer composites broadens the scope of application of FPS [5,6].

It is economically feasible to use gas-filled polymers. Their synthesis is not associated with labor-intensive technology $[7,8]$. The use of industrial waste significantly reduces the

\footnotetext{
* Corresponding author: pehel@yandex.ru
} 
cost of the final product [9-11]. Resil foams have increased stiffness. To reduce stiffness, the authors of [12] introduced linear or weakly branched compounds into the composition of thermosetting plastics to obtain mixed compositions.

The main disadvantages of thermosetting gas-filled polymer foams are high brittleness, reduced strength at relatively high density, increased corrosion activity, propensity for decay, increased content of free phenol and formaldehyde. Reducing corrosion activity expands the scope of such polymers. The authors of [17] propose a polymer composition as an anticorrosion coating for pipelines. In work [18] the possibility of using rigid foam polyurethane foam and the influence of blowing agent on corrosion processes are studied, a technique for studying corrosion, compatibility of polyurethane foams and anticorrosion coatings is proposed. In work [19] the authors touch on the topic of ecological safety of thermal insulation materials and offer measures to reduce the negative consequences.

The urgency of work is determined by the demand for heat-insulating materials based on thermosetting foam plastics.

The purpose of the work is to study the effect of chemical additives on the performance properties of foam plastics.

\section{Materials and Methods}

The starting material is represented by a resolvent foam (type FRP-1). To synthesize it, a phenol-formaldehyde oligomer was used, containing aluminum powder as a blowing agent. As a foaming-curing agent, the condensation product of sulfophenylurea, formaldehyde and orthophosphoric acid is taken. When the oligomer is combined with a blowing agent, an interaction occurs between the aluminum powder and the acidic agent. The process is accompanied by the evolution of hydrogen and isothermal heat. These chemical reaction products are used to provide the required conditions for the foaming and curing of the composition (rate of gas generation and curing), as well as to provide the required apparent density, thermal conductivity, flexural strength and other physical and mechanical properties.

As a result, the finished product of the resolving foam has acidic properties, the acid number is up to $30 \mathrm{mg} \mathrm{KOH} / \mathrm{g}$. The acid number was determined in accordance with GOST 17177-94 Heat-insulating building materials and products. Methods of testing. The multiplicity of the foaming was evaluated by the ratio of the volume of the foamed composition to the primary volume of the raw components.

\section{Results}

In the operating conditions of thermal insulation based on phenol-formaldehyde foam, contact with the metal shows corrosive processes. The corrosive activity of casting polymer foams $\mathrm{s}$ is caused by high values of the acid number. Acid number in the finished products of phenol-formaldehyde foam directly depends on the foaming-curing agent used (FCA) (Fig. 1).

At $20 \%$ content of the foaming-curing agent from the feedstock, the acid number increases threefold to $15 \mathrm{mg} \mathrm{KOH} / \mathrm{g}$, and at $15 \% \mathrm{FCA}$, the acid number increases approximately 2 -fold. Thus, the acid number is directly proportional to the amount of introduced FCA. Consequently, the reduction in the corrosive activity of the finished product is possible by reducing the content of the foaming-curing agent in the preparation of polymer foams. 
Another way to reduce the acid number is the introduction of chemical additives. The experimental data showed that the most effective additive is a mixture of tin (II) chloride dihydrate and calcium oxide in the ratio 2.0: 0.5 (Table 1).

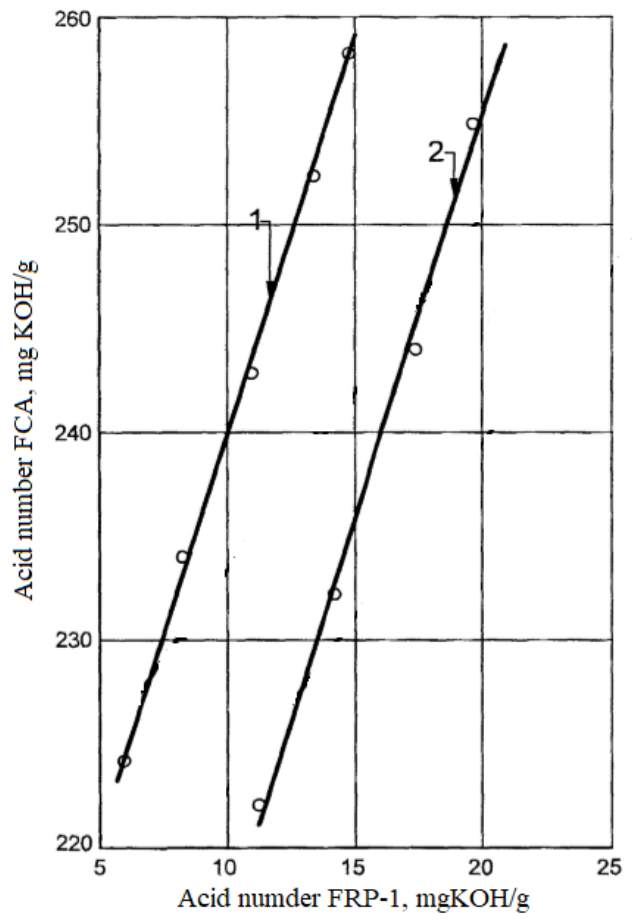

Fig. 1. Dependence of the acid number on the content of the foaming-curing agent: 1 - content of FCA 20\%; 2 - content of FCA $15 \%$.

Table 1. Acid number of modified polymer foams

\begin{tabular}{|c|c|c|c|c|}
\hline Indicators & \multicolumn{4}{|c|}{ Modified foam plastics (FRP-1) } \\
\hline Calcium oxide, wt.\% & 0.5 & 1.0 & 3.0 & 0.5 \\
\hline Tin (II) chloride dihydrate, wt.\% & 0.5 & 1.0 & 1.5 & 2.0 \\
\hline Acid number & 10.1 & 12.3 & 10.7 & 6.74 \\
\hline
\end{tabular}

The maintenance and properties of the finished product depend on the content and acid number of FCA. Studies on the effect of halogenides IA and IIA on the multiplicity and duration of foaming have been carried out. At the first stage, changes in the multiplicity and duration of foaming when salts with the same cation were introduced (Table 2). The cation is an alkali metal cation-potassium, and as anions, halides $\mathrm{Cl}-$; $\mathrm{Br}-$; I-; F-.

Table 2. Performance indicators of modified foam plastics

\begin{tabular}{|c|c|c|c|c|c|}
\hline Indicators & FRP-1 & $\mathrm{KCl}$ & $\mathrm{KBr}$ & $\mathrm{KI}$ & $\mathrm{KF} \cdot 2 \mathrm{H}_{2} \mathrm{O}$ \\
\hline Start time, $\mathrm{s}$ & 105 & 108 & 110 & 110 & 115 \\
\hline Duration of foaming, s & 85 & 80 & 75 & 75 & 65 \\
\hline Froth rate & 25.7 & 26.3 & 27.1 & 27.2 & 29.5 \\
\hline Apparent density, $\mathrm{kg} / \mathrm{m}^{3}$ & 51.0 & 49.8 & 48.2 & 47.8 & 33.6 \\
\hline $\begin{array}{c}\text { Water absorption for } 24 \\
\text { hours, g/cm }\end{array}$ & 0.106 & 0.110 & 0.108 & 0.107 & 0.100 \\
\hline
\end{tabular}

At low fluoride concentrations (up to $1 \%$ by weight), the duration of foaming is reduced by 20-30 seconds. On the basis of the data obtained, a number of optimal actions of metal 
halides have been compiled: $\mathrm{KF} \cdot 2 \mathrm{H}_{2} \mathrm{O}>\mathrm{KC} 1>\mathrm{KBr}>\mathrm{KI}$. These data are consistent with the values of the crystal lattices of the corresponding salts. For such operational properties as apparent density and water absorption, the introduction of chemical additives in the form of potassium halides does not have a noticeable effect. Reduction of the apparent density, as well as of other parameters, is determined by the concentration of the injected salts. The greatest decrease in density is observed with the introduction of fluorides to $0.17 \%$ by weight. The introduction of fluorides greatly affects the multiplicity of foaming and, to a lesser extent, the duration of foaming. For further studies, fluorides are selected that provide the maximum multiplicity of foaming - KF-2 $\mathrm{H}_{2} \mathrm{O}$.

In the second stage, salts with the same anion were used as chemical additives. The investigations were carried out with fluorides of lithium, calcium, potassium, and sodium. The multiplicity of the foaming was determined. With the introduction of sodium fluoride, the multiplicity of foaming increased to 27 , and when lithium fluoride was added to 34 (Fig. 2).

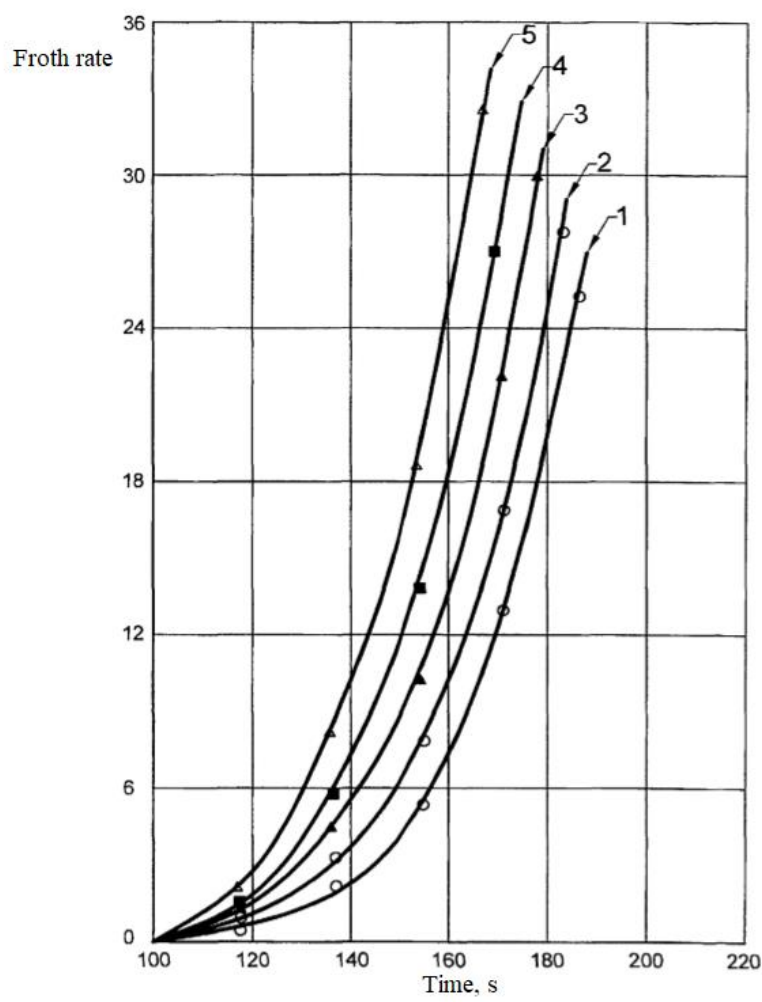

Fig. 2. multiplicity of foaming of compositions containing chemical additives: 1 - FRP-1; 2-NaF; 3 - KF-2 $\mathrm{H}_{2} 0$; 4-CaF 2 ; 5-LiF.

Metal fluorides can be arranged in a series in accordance with their effectiveness: $\mathrm{LiF}>\mathrm{CaF}_{2}>\mathrm{KF} \cdot 2 \mathrm{H}_{2} \mathrm{O}>\mathrm{NaF}$.

\section{Conclusions}

The results of the study show that corrosion activity in products based on FRP-1A resole foam polymer foams can be reduced by the introduction of chemical additives. Reduction of corrosion activity is associated with a decrease in the acid number. It is proposed to use a 
chemical additive containing Tin (II) chloride dihydrate in a mixture with calcium oxide in a ratio of 2: 0.5 .

Analysis of the results of the study on the effect of potassium halides on the multiplicity of foaming showed that potassium fluorides are most effective, and potassium iodide is the least effective. When introducing chemical additives based on fluorides IA and IIA groups, the multiplicity of foaming is maximally increased in the presence of lithium fluoride. Increased foaming materials multiplicity increases the porosity of the product.

Thus, the introduction of chemical additives makes it possible to extend the life of the products even under aggressive conditions and to increase the attractiveness of the material among its competitors. Increasing the multiplicity of foaming makes it possible to obtain foams with lower density, which leads to a decrease in the material consumption of products based on modified foam foams.

\section{References}

1. S. Agarwal, R.K. Gupta, Thermosets (Second Edition) Structure, Properties, and Applications (Elsevier Ltd, Qipeng Guo, 2018)

2. Dr. Richard Heath, Brydson's Plastics Materials (Eighth Edition) (Elsevier Ltd, Marianne Gilbert. 2017)

3. E. Frollini, C. Silva, E. Ramires, Advanced Fibre-Reinforced Polymer (FRP) Composites for Structural Applications (Woodhead Publishing, J Bai, 2013)

4. A. Fangareggi, L. Bertucelli, Thermosets (Second Edition) Structure, Properties, and Applications (Woodhead Publishing, Qipeng Guo, 2012)

5. O. Shepelev, Sam Kenig, Hanna Dodiuk, Handbook of Thermoset Plastics (Third Edition) (Elsevier Inc., Hanna Dodiuk, Sidney H. Goodman, 2014)

6. T. A. Brusentseva, A. A. Filippov, V. M. Fomin, Izvestiya AltGU 1-1 (81), 25-27 (2014)

7. P. S. Liu, G. F. Chen, Porous Materials Processing and Applications (Elsevier Inc. P.S. Liu, G.F. Chen, 2014)

8. A.E. Burdonov, Magazine of Civil Engineering 3 (47), 9-16 (2014)

9. N. Kuznecova, V. P. Archireev, Herald of the Kazan Technological University 5, 9094 (2008)

10. A. E. Burdonov, V. V. Barakhtenko, E. V. Zelinskaya, N. A. Tolmacheva, Stroitel`nye Materialy 1, 48-52 (2015)

11. A. S. Torlova, I. A. Vitkalova, E. A.S. Pikalov, Technical science 2, 96-114 (2017)

12. A. I. Samatadze, I. V. Parakhin, A. S. Tumanov, Proceedings of VIAM, 9, 10 (2014)

13. V. Ushkov, E. Sokoreva, A. Slavin, A. Orlova, Stroitel nye Materialy 11, 28-32 (2014)

14. Chih Pong Chang, Szu Chia Hung, Bioresource Technology 86 (2), 201-202 (2003)

15. V. Ushkov, J. Industrial and Civil Engineering 5, 37-40 (2017)

16. L. Grigoreva, M. Bruyako, Advanced Materials Research 941-944,821 (2014)

17. V. Belyaev, Patent No 2304600 (2007)

18. F. V. V. de Sousa, R. O. da Mota, J. Quintela and etl., Electrochimica Acta, 52 (27), 7780-7785 (2007)

19. E. Velichko, E. Tskhovrebov, A. Shevchenko, MATEC Web of Conferences 106, 03009 (2017) 